\title{
New drugs for the treatment of dry eye disease
}

This article was published in the following Dove Press journal:

Clinical Optometry

28 September 2015

Number of times this article has been viewed

\section{William H Ridder III Apoorva Karsolia}

Southern California College of Optometry, Marshall B Ketchum University, Fullerton, CA, USA
Correspondence: William H Ridder III Southern California College of Optometry, Marshall B Ketchum University, 2575 Yorba Linda Blvd, Fullerton, CA 9283I, USA

Tel + I 7144497494

Fax + I 7|48799834

Email wridder@ketchum.edu
Abstract: Dry eye disease (DED) is one of the most commonly encountered conditions for eye care practitioners. The prevalence of DED can be as high as $30 \%$ of the population. In the past decade, only one drug has been approved for the treatment of DED by the US Food and Drug Administration (FDA) in the USA (ie, Restasis ${ }^{\circledR}$ by Allergan, Inc.). The total annual cost (ie, treatment and lost productivity due to symptoms) to the US economy of dry eye can be more than $\$ 55$ billion. Thus, the development of new drug treatments for dry eye is important for both the dry eye patient and the ophthalmic industry. There are many drugs in development for the treatment of dry eye. This manuscript reviews the drugs listed on the ClinicalTrials.gov website (FDA list of clinical trials) being investigated for the treatment of dry eye. A large number of these drugs are designed to target a specific cause of dry eye and some of these drugs will be approved for clinical use in the next 10 years. This will result in a significant increase in the clinician's choice of treatment and potentially better control of the dry eye patient's condition.

Keywords: keratoconjunctivitis sicca, clinical trials, anti-inflammatory, secretagogues

\section{Introduction}

Dry eye disease (DED) is a condition that affects the tear film and ocular surface and which can impact as much as $20 \%$ of the US population at any one time. ${ }^{1}$ The most recent definition of DED, from a 2007 report by the International Dry Eye WorkShop (DEWS), states that:

Dry eye is a multifactorial disease of the tears and ocular surface that results in symptoms of discomfort, visual disturbance, and tear film instability with potential damage to the ocular surface. ${ }^{2}$

Thus, there are many causes of dry eye that have a broad range of effects.

The two major subtypes of dry eye are aqueous tear-deficient dry eye and evaporative dry eye (EDE). ${ }^{2}$ Dry eye in many patients results from a mixed etiology incorporating aspects of both subtypes. ${ }^{3,4}$ A comprehensive review of the different classes and subclasses of DED was published following the 2007 DEWS, ${ }^{2}$ which included the major etiological causes of dry eye.

Meibomian gland dysfunction (MGD), the most common cause of EDE, ${ }^{5,6}$ has multiple etiologies. ${ }^{7}$ It was recently the focus of an international workshop, which redefined the condition and its treatments. ${ }^{6}$ It can be an acquired or congenital condition, with the most common forms of the acquired being simple and cicatricial MGD. 
These can be primary or secondary to seborrheic dermatitis, acne rosacea, psoriasis, trachoma, or pemphigoid. ${ }^{7}$ Most acquired MGD is due to reduced delivery of meibum to the lid margin in the hyposecretory or obstructive forms of the disease. ${ }^{7}$ Deficiencies in the lipid layer in patients with MGD leads to inability of this layer to effectively inhibit tear film evaporation, resulting in increased rates of evaporation and the condition of EDE. ${ }^{3}$

\section{Epidemiology of DED}

Epidemiological studies of DED report a wide range of prevalence for a variety of reasons. Assessment of agespecific data from large epidemiological studies have given a prevalence range of approximately $5 \%$ to over $30 \% .{ }^{8}$ The lack of a single test that can accurately and reproducibly diagnose DED, the variability and tolerance of symptoms, the lack of correlation between tests, and the use of different diagnostic criteria have contributed to the wide variation in reported prevalence figures. ${ }^{8}$

Studies also indicate that sex and ethnic differences have an influence on the incidence and prevalence of DED. Studies suggest that there is a greater prevalence in women than in men $^{8}$ and that Asian and Hispanic women are more likely than Caucasian women to have a clinical diagnosis of DED and/ or report more severe symptoms. ${ }^{9}$ Recent general population studies of the prevalence of DED indicate that Asian races have approximately twice the incidence of Caucasians. ${ }^{8}$ In addition to sex and ethnicity, a number of other risk factors for DED have been determined. These include older age, 9,10 a low dietary intake of omega-3 essential fatty acids, ${ }^{11}$ androgen deficiency, ${ }^{12}$ vitamin A deficiency, ${ }^{13}$ cataract and refractive surgery, ${ }^{14-16}$ and wearing of contact lenses. ${ }^{17}$ These and other risk factors, arranged by the available supporting level of evidence, are summarized in Table 1.

\section{Symptoms associated with DED}

DED is characterized by symptoms of ocular surface dryness and discomfort due to insufficient tear quantity or quality caused by low tear production and/or excessive tear evaporation. ${ }^{18}$ Common symptoms reported by patients include ocular discomfort, such as dry, scratchy, or burning sensations; pain and stinging; increased blinking; itching and redness; and blurred vision. Diurnal variations exist in these symptoms, with most patients reporting greater symptomatology in the evening. ${ }^{19}$ Symptoms may be exacerbated by reduced and incomplete blinking combined with a decreased tear film break-up time during normal visual tasks. ${ }^{20}$ Donshik et $\mathrm{al}^{21}$ reported the baseline symptomatology of 544 patients with DED entering a Phase III clinical trial. Patients suffered from a variety of symptoms with no one symptom predominating. Daily diaries from patients included reports of foreign-body sensation (29\%), photophobia (27\%), itching

Table I Risk factors for dry eye

\begin{tabular}{|c|c|c|c|}
\hline \multirow[t]{2}{*}{ Category } & \multicolumn{3}{|c|}{ Level of evidence } \\
\hline & Mostly consistent & Suggestive & Unclear \\
\hline \multirow[t]{2}{*}{ Demographics } & Older age & Asian race & Hispanic ethnicity \\
\hline & Female sex & & \\
\hline \multirow[t]{4}{*}{ Medications } & Antihistamines & Tricyclic antidepressants & Anticholinergics \\
\hline & & Selective serotonin reuptake inhibitor & Anxiolytics \\
\hline & & Diuretics & Antipsychotics \\
\hline & & Beta blockers & Oral contraceptives \\
\hline \multirow[t]{4}{*}{ Systemic associations } & Connective tissue disorder & Diabetes mellitus & Acne \\
\hline & Vitamin A deficiency & HIV/HTLVI infection & Gout \\
\hline & Hepatitis C infection & Sarcoidosis & Menopause \\
\hline & Androgen deficiency & Ovarian dysfunction & Pregnancy \\
\hline \multirow[t]{5}{*}{ Prior treatment or surgery } & Postmenopausal estrogen therapy & Systemic chemotherapy & Botulinum toxin injection \\
\hline & Radiation therapy & Isotretinoin & \\
\hline & Hematopoietic stem cell transplantation & Large-incision ECCE and penetrating & \\
\hline & & keratoplasty & \\
\hline & LASIK and refractive excimer laser surgery & & \\
\hline \multirow[t]{2}{*}{ Miscellaneous } & Omega- 3 and Omega- 6 fatty acids & Low-humidity environment & Cigarette smoking \\
\hline & & & Alcohol \\
\hline
\end{tabular}

Notes: Mostly consistent evidence implies the existence of at least one adequately powered and otherwise well-conducted study published in a peer-reviewed journal, along with the existence of a plausible biological rationale and corroborating basic research or clinical data. Suggestive evidence implies the existence of either: I) inconclusive information from peer-reviewed publications; or 2) inconclusive or limited information to support the association, but either not published or published somewhere other than in a peer-reviewed journal. Unclear evidence implies either directly conflicting information in peer-reviewed publications or inconclusive information but with some basis for a biological rationale. Modified from: The Ocular Surface. 5(2), [No authors listed], The epidemiology of dry eye disease: report of the Epidemiology Subcommittee of the International Dry Eye WorkShop (2007), 93-107, Copyright 2007, with permission from Elsevier. ${ }^{8}$

Abbreviation: ECCE, extracapsular cataract extraction. 
(21\%), and burning/pain (11\%). ${ }^{21}$ Another study has shown that there is little correlation between the severity or type of symptoms experienced and the clinical manifestations of the disease. ${ }^{22}$

However, it should be noted that poor correlations have been found between symptoms reported by patients and clinical DED tests. ${ }^{23}$ Patient symptoms have been observed to be better correlated with a global clinician grade of DED. ${ }^{19}$ This may imply that severity grading of DED is more influenced by patient symptoms than clinical test results. ${ }^{19}$

Dry eye symptoms can result in a significant financial cost to society. In the USA alone, the cost of medical care for dry eye patients has been reported to be as high as $\$ 3.84$ billion per year. ${ }^{24}$ If other factors such as the loss of productivity of dry eye patients are included, then the annual costs can be $\$ 55.4$ billion. ${ }^{24}$ Thus, the development of new treatments for dry eye can have a significant impact on the individual dry eye patients as well as society as a whole.

Table 1 demonstrates that there are many factors associated with the development of dry eye and the symptoms that it causes are varied. Since there are many causes of dry eye, a variety of new drugs with different mechanisms of action will need to be developed to address these causes. This will result in a significant expansion in the field of dry eye treatment. In fact, GlobalData predicted on June 12 , 2013 that the compound annual growth rate until the year 2022 will be $12.8 \%$ for dry eye drug sales in Europe, Asia, and the USA. ${ }^{25}$ The growth will result from an increased number of patients with dry eye and new improved drugs for its treatment.

\section{Current treatments for DED}

The DEWS reviewed the current treatments for dry eye (Figure 1) and ranked those treatments based on the therapeutic effect reported in the clinical and research literature. ${ }^{26}$ They suggested that the treatment should be based on the severity of the dry eye condition. The DEWS report listed artificial tear supplements, gels, moisture chamber spectacles, anti-inflammatory agents, tetracyclines, punctal plugs, secretagogues, serum, contact lenses, systemic immunosuppressives, and surgery as accepted treatments for dry eye. ${ }^{26}$ This review will discuss the drugs that have been investigated since the DEWS report. The drugs that have been in clinical trials for dry eye are listed in Table 2. Many of the drugs discussed in the following section are in early stages of development and may not have been described in peer-reviewed published papers. Thus, much of the following information is taken from the ClinicalTrials.gov website, which was started following the US Food and Drug Administration Modernization Act of 1997.

Table 2 organizes the drugs based on the phase of the clinical trial. Phase I trials are testing a new drug on a small group of people to determine its safety and side effects. Phase II trials are using the drug on a greater number of people to see if it is effective and further assess safety. Phase III trials use the drug on a large number of patients to confirm effectiveness, monitor side effects, compare it to other treatments, and collect information to allow the drug to be used safely. Phase IV studies are done after the drug has been marketed to look at its effect on different populations and look for side effects associated with long-term use.

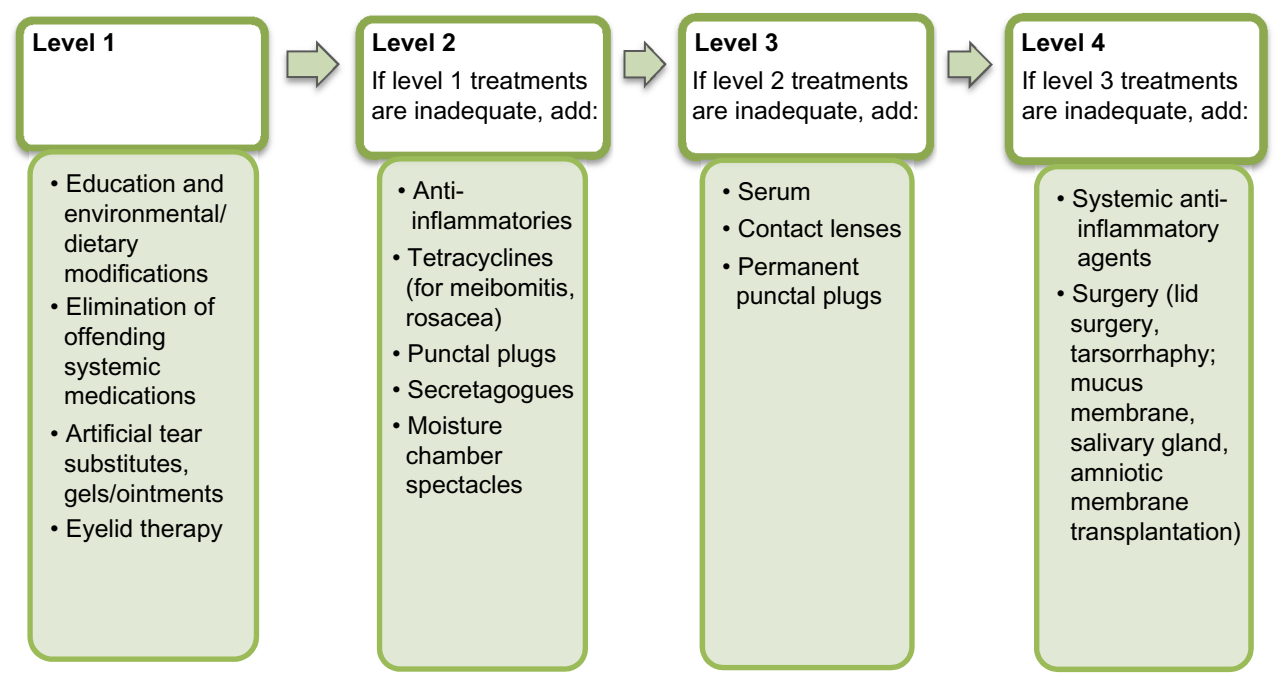

Figure I Treatment recommendations by severity level.

Notes: Modified from: Behrens A, Doyle J], Stern L, et al. Dysfunctional tear syndrome: A Delphi approach to treatment recommendations. Cornea. 2006;25(8):900-907. Copyright (C) 2006, (C) 2006 Lippincott Williams. With permission from Wolters Kluwer Health, Inc. ${ }^{80}$ 
Table 2 Dry eye disease drugs under development

\begin{tabular}{|c|c|c|c|c|}
\hline Phase & Manufacturer/sponsor name & Drug name & $\begin{array}{l}\text { ClinicalTrials. } \\
\text { gov identifier }\end{array}$ & $\begin{array}{l}\text { Study completion } \\
\text { date }\end{array}$ \\
\hline Phase IV & Merck Sharp and Dohme Corp & Azithromycin & $\begin{array}{l}\text { NCTOIOI } 4078 \\
\text { and NCTOII } 05624\end{array}$ & $\begin{array}{l}\text { March } 2010 \text { and } \\
\text { November } 2010\end{array}$ \\
\hline \multirow[t]{12}{*}{ Phase III } & Santen Pharmaceutical Co. & Cyclosporine A (NOVA22007) & NCT008I45I5 & September 2009 \\
\hline & Eyegate Pharmaceuticals, Inc. & Dexamethasone phosphate (EGP-437) & NCT0II 29856 & April 20II \\
\hline & $\begin{array}{l}\text { ISTA Pharmaceuticals, Inc. and Bausch \& } \\
\text { Lomb Incorporated }\end{array}$ & Bromfenac & NCT0 I 2 I $247 \mid$ & December 2011 \\
\hline & Merck and Co, Inc. & Diquafosol tetrasodium (DE-089) & NCTOII0I984 & April 2012 \\
\hline & Sanofi-Aventis & Hydroxychloroquine & NCT00632866 & May 2012 \\
\hline & Acucela Inc. and Otsuka Pharmaceutical Co, Ltd & Rebamipide (OPC-12759) & NCT01632137 & June 2013 \\
\hline & Can-Fite BioPharma & CFIOI & NCT0I 235234 & December 2013 \\
\hline & Shire & Lifitegrast (SAR II8) & $\begin{array}{l}\text { NCT0I } 636206 \\
\text { and NCT022845I }\end{array}$ & $\begin{array}{l}\text { March } 2014 \text { and } \\
\text { September } 2015\end{array}$ \\
\hline & Mimetogen Pharmaceuticals USA, Inc. & MIM-D3 & NCT0I9600I0 & August 2014 \\
\hline & Eleven Biotherapeutics & EBI-005 & NCTOI998802 & April 2015 \\
\hline & DH Bio Co, Ltd & Cyclosporine (Haporine-S) & NCT0I80436I & February 2014 \\
\hline & Alcon Research & Rimexolone (AL-2|78) & NCT0047I4I9 & August 2007 \\
\hline \multirow[t]{3}{*}{ Phase II/III } & Bausch \& Lomb Incorporated & Ecabet sodium & NCT00I98536 & December 2005 \\
\hline & IDEC Pharmaceuticals & Rituximab & NCT00740948 & January 2013 \\
\hline & Hoffmann-La Roche Ltd & Tocilizumab & NCT0I782235 & March 2017 \\
\hline \multirow[t]{12}{*}{ Phase II } & Michigan Cornea Consultants, PC & Thymosin beta-4 eyedrops (RGN-259) & NCT0I393I32 & December 2012 \\
\hline & Mitotech, SA & SkQI & NCT02I2I30I & May 2014 \\
\hline & Kala Pharmaceuticals, Inc. & KPI-I2I & NCT02188I60 & March 2015 \\
\hline & Herantis Pharma Plc & cis-UCA & NCT02326090 & April 2015 \\
\hline & Alcon Research & LME636 & NCT023655I9 & October 2015 \\
\hline & Allergan & AGN-223575 & NCT024359|4 & December 2016 \\
\hline & InSite Vision & ISV-I0I (bromfenac in DuraSite) & NCT0I478555 & January 2017 \\
\hline & Ocular Therapeutix, Inc. & OTX-DP & NCT02468700 & December 2015 \\
\hline & Allergan & Cyclosporine (Restasis $X^{\circledR}$ ) & NCT020I379I & July 2017 \\
\hline & Santen Pharmaceutical Co. & Rivoglitazone (DE-IOI) & NCT0I468I 68 & November 2012 \\
\hline & Bausch \& Lomb Incorporated & Mapracorat (BOL-303242-X) & NCTOII 63643 & July 2011 \\
\hline & Resolvyx & Resolvin (RX-10045) & NCT00799552 & June 2009 \\
\hline \multirow[t]{4}{*}{ Phase I/II } & Pfizer & Tasocitinib/tofacitinib (CP-690550) & NCT007847I9 & October 2009 \\
\hline & R-Tech Ueno, Ltd & RU-I0I & NCT0I843894 & July 2014 \\
\hline & Genentech, Inc. & DNase & NCT02193490 & December 2016 \\
\hline & Lux Biosciences & Voclosporin (LX2|4) & NCT0085I734 & April 2009 \\
\hline \multirow[t]{3}{*}{ Phase I } & Parion Sciences & $\mathrm{P}-321$ & NCT02242032 & March 2015 \\
\hline & Stemnion, Inc. & ACCS & NCT0236986I & December 2015 \\
\hline & Allergan & AGN-2324II & NCT02420730 & June 2016 \\
\hline
\end{tabular}

Abbreviations: ACCS, amnion-derived cellular cytokine solution; cis-UCA, cis-urocanic acid.

Drugs in the later-phase studies have passed many hurdles in the US Food and Drug Administration (FDA) approval process and are closer to being approved and marketed for clinical use.

\section{New drug treatments for DED Anti-inflammatory drugs Corticosteroids and nonsteroidal anti-inflammatory drugs \\ Dexamethasone phosphate}

Dexamethasone is a glucocorticoid with anti-inflammatory and immunosuppressive properties. Dexamethasone phosphate (EGP-437) is manufactured by EyeGate Pharmaceuticals, Inc.
(Waltham, MA, USA) as a treatment for dry eye. The drug is administered by iontophoresis to increase drug permeability to the tissue. In a Phase II study (http://www.ClinicalTrials. gov identifier: NCT00765804), ${ }^{27}$ a total of 105 patients were randomized to a low drug dose $(7.5 \%)$, a high drug dose $(10.5 \%)$, or a placebo group. The treatment groups showed statistically significant improvements in signs and symptoms of dry eye at various time points; however, the primary endpoints were not achieved. The primary endpoints of the study concerned ocular discomfort and corneal staining at study visit 5 . These were not statistically different among the treatment groups. Adverse events were common, but most were mild, and no severe adverse events were observed. 
A Phase III clinical trial (NCT01129856) with 198 patients was completed in April 2011 in which two different concentrations of EGP-437 were compared to placebo in a controlled adverse environment. ${ }^{27}$ Results of this study have not been released.

\section{Rimexolone}

Alcon Laboratories, Inc. (Fort Worth, TX, USA) developed the anti-inflammatory drug rimexolone (AL-2178). Rimexolone inhibits cytokine production of activated CD4 T-cells and it inhibits T-cell proliferation. Vexol 1\% (rimexolone) is on the market as an ophthalmic suspension. It is approved to treat postoperative inflammation after ocular surgery and anterior uveitis. A Phase III interventional randomized double-blind study (NCT00471419) which had a projected enrollment of 750 dry eye patients was completed in August 2007. The ClinicalTrials.gov website was last updated in 2012, but the results have not been entered. Vexol, similar to other steroids like Lotemax (Bausch \& Lomb Incorporated, Bridgewater, NJ, USA), Alrex (Bausch \& Lomb Incorporated), and FML ${ }^{\circledR}$ (Allergan, Inc., Irvine, CA, USA), have been used off-label to treat dry eye.

\section{Loteprednol etabonate}

Kala Pharmaceuticals, Inc. (Waltham, MA, USA) is developing KPI-121. KPI-121 uses mucus-penetrating particle technology developed by Kala Pharmaceuticals, Inc. KPI-121 is loteprednol etabonate. The results of a Phase II clinical trial (NCT02188160) were recently (April 1, 2015) reported on by Kala Pharmaceuticals, Inc. ${ }^{28}$ The trial used $0.25 \%$ KPI- 121 four times per day on 150 dry eye patients. The results achieved statistical significance for the primary clinical sign endpoint (ie, bulbar conjunctival hyperemia, $P=0.0387$ ). There was not a statistical improvement in dry eye symptoms. The drug was well tolerated in the study, with the most common adverse event being instillation site pain in $6.9 \%$ of the patients. Instillation site pain was reported in $3.8 \%$ of the patients on vehicle.

\section{Dexamethasone}

Ocular Therapeutix, Inc. (Bedford, MA, USA) is developing OTX-DP. This is a sustained-release dexamethasone that is administered as a one-time absorbable intracanalicular plug. The plug delivers a 4-week tapered dose of dexamethasone. It is being developed: to treat ocular inflammation and pain following cataract surgery; to treat allergic conjunctivitis; and as a possible treatment for dry eye. Two Phase III studies (NCT02034019 and NCT02089113) which enrolled 247 cataract patients were just recently completed. The company reported that OTX-DP met both primary efficacy measures, achieving a statistically significant improvement in the reduction of inflammatory cells and pain in cataract patients.

A Phase II study (NCT02468700) is ongoing to assess the safety and efficacy of OTX-DP ( $0.4 \mathrm{mg}$ dexamethasone) in dry eye patients. The study is expected to enroll 43 dry eye patients and the completion date is December 2015. No study results are available.

\section{Bromfenac}

Bromfenac, a nonsteroidal anti-inflammatory drug, was developed by ISTA Pharmaceuticals, Inc. (Irvine, CA, USA) and Bausch \& Lomb Incorporated. An animal study indicates that concentrations of $0.07 \%$ and $0.09 \%$ penetrate the ocular tissues well. ${ }^{29}$ In humans, following cataract surgery, it has a good safety profile. ${ }^{30}$ The results of a Phase II clinical trial (NCT00758784) with 38 dry eye patients indicated that a low dose of bromfenac $(0.09 \%)$ was effective at statistically decreasing conjunctival (lissamine green test) and corneal (sodium fluorescein test) staining from baseline. Patients also achieved statistically significant improvements in subjective symptoms measured by the Ocular Surface Disease Index (OSDI). A randomized, interventional, Phase III study (NCT01212471) was carried out to evaluate safety and efficacy of bromfenac ophthalmic solution in DED. A total of 840 subjects were enrolled in the study, which was completed in December 2011. The results have not been posted on the ClinicalTrials.gov website. Bromfenac is marketed with the brand names of Xibrom, Prolensa, and Bromday.

A recent publication reported the effect of bromfenac use in 26 dry eye patients. ${ }^{31}$ Patients were chosen that were inadequately controlled with artificial tears. They reported that the addition of bromfenac to the artificial tear use resulted in an improvement in corneal staining, tear film breakup time, and subjective dryness scores, but no improvement in Schirmer scores. No adverse events were reported.

\section{Cytokine inhibitors}

\section{EBI-005}

Eleven Biotherapeutics (Cambridge, MA, USA) has developed the interleukin (IL)-1 receptor antagonist EBI-005 for the treatment of DED. ${ }^{32}$ EBI-005 is the end product of joining two IL-1 receptor ligands (IL-1 $\beta$ and IL-1Ra). EBI-005 was optimized for ocular delivery and binds to IL-1R1. An animal study with mouse models of dry eye indicated that topical formulations of 5\% IL-1Ra result in decreased corneal staining. ${ }^{33}$ A Phase Ib/IIa study (NCT01745887) with 74 dry eye patients was completed in November 2012. The 
results, although not statistically significant, suggested that EBI-005 improved signs and symptoms of dry eye. There were no adverse events in this study and the drug was well tolerated. A Phase III (NCT01998802) multicenter, doublemasked, randomized, efficacy and safety study of EBI-005 ( $5 \mathrm{mg} / \mathrm{mL}$ topical ophthalmic solution) versus vehicle completed enrollment of 670 patients in early 2015. Results were recently reported at an Association for Research in Vision and Ophthalmology (ARVO) meeting. ${ }^{34}$ The authors indicated that using EBI-005 three times per day for 6 weeks is safe and well tolerated. There were no treatment-related serious ocular or nonocular adverse events. There was a significant improvement in signs and symptoms at 6 weeks compared to baseline $(P<0.001)$.

\section{Tocilizumab}

Tocilizumab is being developed by Hoffmann-La Roche Ltd (Basel, Switzerland). Tocilizumab is an IL-6 inhibitor that is approved to treat rheumatologic and autoimmune disease. ${ }^{35}$ Preclinical animal studies have not found tocilizumab to cause ocular or systemic toxicity. ${ }^{36}$ A randomized, doubleblind, placebo-controlled Phase II/III trial to evaluate the efficacy of tocilizumab for the treatment of primary Sjögren's syndrome is in progress (NCT01782235). The study will be completed in March 2017 and has an estimate of 110 enrolled subjects.

\section{CFIOI}

Can-Fite BioPharma Ltd (Petah-Tikva, Israel) is developing CF101 as an oral drug to treat dry eye. CF101 is an antiinflammatory drug (an $\mathrm{A}_{3}$ adenosine receptor agonist) that modulates signaling proteins like P13K, PKA, PKB/Akt,

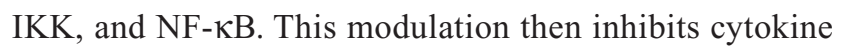
production. Several animal studies have reported the antiinflammatory effects of CF101 in arthritis, inflammatory bowel disease, osteoarthritis, and septic peritonitis. ${ }^{37-42}$ The results of a Phase II study (NCT00349466) in dry eye patients were recently reported. ${ }^{43}$ Sixty-eight (35 on placebo and 33 on CF101) patients completed the study. Treatment with CF101 resulted in a statistically significant improvement in the mean change from baseline to week 12 of the corneal staining, tear breakup time, and tear meniscus height in the CF101-treated group. The authors reported that CF101 was well tolerated and exhibited an excellent safety profile with no serious adverse events. ${ }^{43}$ A Phase III study (NCT01235234) of the safety and efficacy of daily IB-MECA CF101 (0.1 mg or $1 \mathrm{mg})$ administered orally in patients with moderate-to-severe DED was completed in December 2013. The final results have not been reported.

\section{T-cell inhibitors \\ Cyclosporine A}

Cyclosporine A $(0.05 \%)$ is currently marketed in the USA

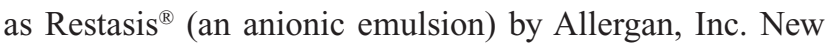
versions of cyclosporine $\mathrm{A}$ are being investigated to improve bioavailability, increase absorption rate, and reduce dosage. Allergan, Inc. is currently testing Restasis X in a Phase II study (NCT02013791) that will enroll 138 subjects (moderate-to-severe dry eye). This study will not be completed until July 2017.

\section{Cyclosporine A NOVA22007}

Santen Pharmaceutical Co. (Osaka, Japan) (formerly known as Novagali Pharma) is developing NOVA22007 (cyclosporine A). NOVA22007 is a cationic nanoemulsion. ${ }^{44}$ Preclinical studies suggested that a cationic emulsion may be superior to an anionic emulsion. ${ }^{44,45}$ Two Phase II studies have been carried out. The initial trial enrolled 53 Sjögren's patients. The purpose of this study was to assess ocular tolerance and systemic safety of three concentrations of cyclosporine A $(0.025 \%, 0.05 \%$, and $0.1 \%)$. Over the 3 -month trial, there were no safety concerns. The $0.1 \%$ concentration resulted in the greatest improvement in corneal and conjunctival staining over the 3 -month trial. The second Phase II trial (NCT00739349) examined 132 mild-to-moderate dry eye patients over 3 months using the controlled adverse environment chamber. Two concentrations of cyclosporine A were examined $(0.05 \%$ and $0.1 \%)$. A significant improvement in corneal staining and ocular discomfort was not found. Santen Pharmaceutical Co. received FDA approval for a Phase III trial (NCT00814515) in the USA with NOVA22007 in moderate-to-severe dry eye. The estimated enrollment was 482 patients. The study was completed in 2009 but the results of the Phase III trial have not been released.

In Europe, NOVA22007 is called Ikervis. In January 2015, the Committee for Medicinal Products for Human Use of the European Medicines Agency recommended the granting of a marketing authorization for Ikervis $(1 \mathrm{mg} / \mathrm{mL}$ cyclosporine) ${ }^{46}$ It is approved to treat severe keratitis in adult dry eye patients.

\section{Haporine-S}

$\mathrm{DH}$ Bio Co, Ltd is investigating the development of cyclosporine A (Haporine-S) as a nanoparticle. This is believed to increase the absorption rate and allow for dose reduction. A Phase III study (NCT01804361) to compare the efficacy and safety of topical Haporine-S versus Restasis $(0.05 \%)$ in patients with moderate-to-severe DED was com- 
pleted in February 2014 with an enrollment of 90 subjects. The final results are not posted on the ClinicalTrials.gov website.

\section{Lifitegrast}

Lifitegrast (SAR 1118) ophthalmic solution (5\%) is being investigated by Shire (Lexington, MA, USA). Lifitegrast is a small-molecule integrin inhibitor. It binds to lymphocyte function-associated antigen-1 (LFA-1) and blocks the interaction of LFA-1 with ICAM-1. This results in a decrease in T-cell activation. One Phase III study is complete (NCT01636206) and a second is ongoing (NCT02284516). The first study evaluated the safety of a $5.0 \%$ concentration of lifitegrast ophthalmic solution compared to a placebo in dry eye subjects. A total of 332 subjects were enrolled in the study, which was completed in March 2014. The second Phase III study is still recruiting patients. It is expected to enroll 700 patients and the study will be completed in September 2015. Some of the results have been published. ${ }^{47,48}$ Sheppard et al, reported that lifitegrast met the primary objective of the study in comparison to the placebo. This was a significant decrease in inferior corneal staining $(P=0.0007)$. It also significantly reduced superior $(P=0.0392)$ and total $(P=0.0148)$ corneal fluorescein staining and conjunctival lissamine staining (nasal, $P=0.0039$; total conjunctiva, $P=0.0086$ ) at day 84 versus placebo. The study did not meet the co-primary subjective measure of the visual-related function subscale score of the OSDI $(P=0.7894)$. There were no unanticipated or serious ocular adverse events. ${ }^{47}$ Based on these results, Shire has applied for a new drug application with the FDA for lifitegrast for the treatment of dry eye. A decision by the FDA is expected in October 2015.

\section{mRNA translation inhibitors}

Azithromycin

Azithromycin ophthalmic solution (1\%) was developed by Merck and Co, Inc. (Kenilworth, NJ, USA). Azithromycin demonstrates antibacterial, anti-inflammatory, and immunomodulatory properties. Two Phase IV studies (NCT01014078 and NCT01105624) have been carried out. The objective of the first study was to compare the safety and efficacy of $1 \%$ azithromycin ophthalmic solution in dry eye subjects over a 4-week treatment period using placebo as a comparison. The study enrolled 112 subjects and was completed in March 2010. The second trial compared azithromycin to rewetting drops in patients that complained of a contact lens-related dry eye. This study enrolled 50 patients and was completed in November 2010. These studies indicated that topical treat- ment with azithromycin was well tolerated and improved contact lens wearing time. ${ }^{49,50}$

\section{Hemozoin biocrystallization inhibitors Hydroxychloroquine}

Hydroxychloroquine, a hemozoin biocrystallization inhibitor, was developed by the Public Hospital of Paris (Paris, France) in collaboration with Sanofi-Aventis (Bridgewater, NJ, USA) for the treatment of DED. An interventional randomized placebo-controlled Phase III clinical trial (NCT00632866) on the safety of hydroxychloroquine ( $200 \mathrm{mg}$ /day for 24 weeks) in primary Sjögren's syndrome enrolled 120 subjects and was completed in May 2012. The published results indicate that hydroxychloroquine compared to placebo did not improve symptoms in primary Sjögren's syndrome patients. ${ }^{51}$ However, there are publications suggesting that hydroxychloroquine increases tear production in dry eye patients and improves symptomology. ${ }^{52,53}$ Thus, hydroxychloroquine may prove beneficial in treating dry eye, but because of some of its severe side effects (ie, toxic retinopathy, cramps, dizziness, headache), it may not be practical. ${ }^{54,55}$

\section{B-cell antibodies \\ Rituximab}

IDEC Pharmaceuticals (San Diego, CA, USA) has developed rituximab. A multicenter, randomized, double-blind, placebo-controlled Phase II/III clinical trial (NCT00740948) was conducted by the University Hospital of Brest (Brest, France) to study the tolerance and efficacy of rituximab in Sjögren's syndrome. The study enrolled 120 subjects and was completed in January 2013. Rituximab (1 g) was injected two times on the first day and one time on the 14th day of the trial. The placebo was sodium chloride or glucose. The results of this study were recently reported. ${ }^{56}$ No significant difference was found at the primary endpoint between the rituximab and placebo groups. Adverse events were similar between groups except for a higher rate of infusion reactions with rituximab. It was concluded that rituximab alleviated some symptoms at earlier time points but not in patients with primary Sjögren's syndrome at week 24.

\section{Mucin secretagogues MIM-D3}

Mimetogen Pharmaceuticals (Gloucester, MA, USA) developed a mucin agonist called MIM-D3. MIM-D3 is a partial agonist of the nerve growth factor (NGF) receptor TrkA. A Phase III clinical study (NCT01960010) of 1\% MIM-D3 ophthalmic solution was recently completed in August 2014. A total of 403 subjects were recruited 
in the study. MIM-D3 was well tolerated. The company reported that improvements over the placebo were seen for corneal staining and the OSDI questionnaire. A recent report at an ARVO meeting also indicated that MIM-D3 $1 \%$ resulted in improvements in signs and symptoms in dry eye patients. ${ }^{57}$

\section{Rebamipide}

Acucela Inc. (Seattle, WA, USA) and Otsuka Pharmaceutical Co, Ltd (Tokyo, Japan) investigated rebamipide (OPC-12759) for the treatment of dry eye. Rebamipide was approved in Japan in 2011 to treat dry eye and it is currently marketed in the People's Republic of China, Japan, Indonesia, Malaysia, and Thailand. Rebamipide is an amino acid analog of $2(1 \mathrm{H})-$ quinolinone and increases mucin levels over the conjuctiva and cornea. ${ }^{58,59}$ It upregulates the gene and protein expression of MUC1, MUC4, and MUC16 in human corneal epithelial cells. ${ }^{60,61}$ It has recently been shown to increase epithelial cell proliferation. ${ }^{62}$ A Phase III clinical trial (NCT01632137) was recently completed (June 2013) in which rebamipide 2\% was used four times per day. Several reports have indicated that rebamipide is safe, well tolerated, and effective in decreasing the signs and symptoms of dry eye. ${ }^{63,64}$ In dry eye patients with short tear breakup times, rebamipide use for 4 weeks (four times per day of $2 \%$ rebamipide) has been shown to improve post-blink higher-order aberrations $(P<0.05)$ and increase tear breakup times $(P<0.001)$.

\section{Ecabet sodium}

Bausch \& Lomb Incorporated was developing ecabet sodium, a drug that stimulates mucous secretion. Ecabet sodium is marketed in Japan by Senju Pharmaceuticals (Osaka, Japan) as an oral drug for gastric ulcers. A Phase II/III clinical trial (NCT00198536) was sponsored by Bausch \& Lomb Incorporated. The efficacy and safety of ecabet ophthalmic solution (2.83\% and $3.70 \%)$ was examined in 159 enrolled patients. The study was completed in 2005. Results were not reported on the ClinicalTrials.gov website. Two other Phase II studies (NCT00370747, NCT00667004) were carried out by Bausch \& Lomb Incorporated from 2006 to 2008. These were designed to examine the safety and efficacy of ecabet sodium applied four times per day in dry eye patients. A total of 345 dry eye patients were to be enrolled. No results from these studies have been released.

\section{Diquafosol tetrasodium}

Diquafosol tetrasodium, developed by Merck and Co, Inc. is a P2Y2 receptor agonist used to treat dry eye. It is a stable derivative of uridine $5^{\prime}$-triphosphate. It increases mucin and fluid secretion. ${ }^{65-67}$ Diquas ophthalmic solution (diquafosol tetrasodium 3\%, six times per day) was approved in 2010 by the Japanese Ministry of Health, Labor and Welfare to treat dry eye. It is also approved for use in Korea. A Phase III clinical trial (NCT01101984) by Santen Pharmaceutical Co was completed in April 2012 with 400 enrolled subjects. An early report indicated that diquafosol 3\% was well tolerated and had a good safety profile. ${ }^{68}$ It was better than sodium hyaluronate $(0.1 \%)$ in improving conjunctival staining. Corneal staining was the same for the two ophthalmic solutions. More recently, the results of this clinical trial have been published with a greater number of patients. ${ }^{69} \mathrm{~A}$ total of 497 patients were evaluated in this report. The corneal and conjunctival staining results were the same as in the earlier publication by Takamura et al. ${ }^{68}$ The most common adverse events for diquafosol were eye discharge (4.5\%), eye itching (3.3\%), and eye irritation (2.8\%). The adverse event rate for hyaluronic acid was less than that for diquafosol. A recent review of publications concerning 3\% diquafosol tabulated reported drug reactions. ${ }^{70}$ Adverse events were reported in $23.7 \%$ of the 655 patients enrolled in clinical trials with diquafosol. The drug reactions reported were eye irritation (6.7\%), eye discharge (4.7\%), conjunctival injection $(3.7 \%)$, eye pain $(2.7 \%)$, eye pruritus $(2.4 \%)$, foreign body sensation $(2.1 \%)$, and eye discomfort (1.1\%). Most of these reactions were mild. In summary, $3 \%$ diquafosol tetrasodium improves dry eye signs as good as, if not better than, hyaluronic acid, but the incidence of mild side effects is greater.

\section{Early-stage drugs for dry eye (Phase I/II)}

In addition to the drugs discussed earlier, there are many drugs that are in the early stages of development for treatment of dry eye. For example, Allergan, Inc. has two compounds (AGN-232411 and AGN-223575) in Phase I or II trials (NCT02420730 and NCT02435914). Neither of these trials are enrolling subjects yet and their expected completion date is 2016. Alcon, Inc. has a Phase II study (NCT02365519) of LME636 that is currently enrolling subjects. The expected completion date is October 2015. Stemnion, Inc. (Pittsburgh, PA, USA) also has a Phase I study (NCT02369861) with their drug ACCS (amnion-derived cellular cytokine solution). It is also enrolling subjects and has an expected completion date of December 2015. Genentech, Inc. (South San Francisco, CA, USA) has DNase (0.1\%) in a Phase I/II study (NCT02193490). This study is examining the safety and efficacy of recombinant human DNA in Sjögren's patients. 
The expected completion date is December 2016. Herantis Pharma Plc (Helsinki, Finland) recently completed a Phase II study (NCT02326090) of cis-urocanic acid (1\% and 2.5\%). No results are posted. InSite Vision (Alameda, CA, USA) is planning a Phase II study (NCT01478555) to examine the safety and efficacy of ISV-101 (bromfenac in DuraSite) in dry eye patients. The study start date is January 2016. Parion Sciences (Durham, NC, USA) just completed a Phase I study (NCT02242032) of P-321 ophthalmic solution in 53 dry eye subjects. The purpose of the study was to assess the safety and efficacy of P-321. The results have not been posted.

Michigan Cornea Consultants, PC (Southfield, MI, USA) completed a Phase II study (NCT01393132) of thymosin beta-4 (T $\beta 4)$ eyedrops (RGN-259) in severe dry eye patients. $\mathrm{T} \beta 4$ promotes healing of the corneal surface. The results of a study on a mouse model of wound healing demonstrated that T $\beta 4$ reduces wound healing time. ${ }^{71}$ In the Phase II study (NCT01393132), nine patients with severe dry eye were treated with either RGN-259 $(0.1 \%)$ or vehicle control six times per day. The results of the study suggest that RGN-259 is safe and well tolerated. The treated dry eye patients also had a reduction in signs and symptoms. ${ }^{72}$ A second Phase II trial (NCT01387347), with 72 dry eye subjects, was completed in December 2011. No adverse events were reported for $\mathrm{T} \beta 4$. The company reported an improvement in signs and symptoms on the ClinicalTrials.gov website.

Mitotech, SA (Moscow, Russia) completed a Phase II study (NCT02121301) with SkQ1 for the treatment of dry eye in 91 patients. SkQ1 is a drug designed to reduce oxidative stress in mitochondria. The results were reported at the 2015 ARVO meeting. ${ }^{73}$ The authors reported that SkQ1 was safe and the drug decreased total corneal staining and improved symptoms.

R-Tech Ueno, Ltd (Tokyo, Japan) is developing RU-101, an ophthalmic solution containing recombinant human serum albumin. This mechanism of action is different from other drugs currently under development to treat dry eye. A Phase I/II clinical trial (NCT01843894) was recently completed (July 2014). The study was designed to determine the safety and efficacy of RU-101 in 104 dry eye patients. RU-101 was instilled six times per day for 4 weeks. The company reported a significant improvement in the corneal staining score at 4, 8, and 12 weeks after starting instillation. However, the corneal staining score did not reach statistical significance when compared to placebo. No safety concerns were reported.

Rivoglitazone (DE-101) is an anti-inflammatory drug developed by Santen Pharmaceutical Co. It is a peroxi- some proliferator-activated receptor gamma agonist which directly acts on corneal and conjunctival epithelial cells by enhancing the barrier function of the epithelium. In a Phase II (NCT01468168) randomized placebo-controlled trial, high and low doses of DE-101 were compared to placebo in patients with dry eye. An estimated 183 subjects were enrolled in the study, which was completed in November 2012. In August 2013, Santen Pharmaceutical Co. discontinued the development of DE-101 as the drug was judged to be unable to meet achievement criteria. No study results were reported.

RX-10045 is an immune response mediator derived from resolvin, which is a group of lipid modulators derived from naturally occurring omega-3 fatty acids. RX-10045, developed by Resolvyx (Cambridge, MA, USA), helps to resolve inflammation and promote healing in dry eye. In murine models, a treatment regimen of resolvin was found to reverse corneal epithelial damage associated with dry eye as well as improve both corneal staining and goblet cell density. ${ }^{74,75}$ A 28-day, randomized, multicenter, placebocontrolled Phase II study (NCT00799552) in 232 patients with moderate dry eye was completed in June 2009. Three different doses of RX-10045 were compared to placebo to evaluate the safety, tolerability, and efficacy of RX-10045 administered twice daily. The company reported that RX-10045 produced a dose-dependent, statistically significant improvement in the primary endpoints for both the signs and symptoms of dry eye, and was generally shown to be safe and well tolerated. However, final data have not been published.

Voclosporin (LX214) is an anti-inflammatory drug developed by Lux Biosciences (Jersey City, NJ, USA) which acts against calcineurin and enhances metabolic stability. In a Phase I (NCT00851734) dose escalation study to assess the safety and tolerability of LX214, 35 patients with dry eye were randomized into LX214 (0.02\% and 0.2\%) and placebo. The study was completed in April 2009. The company website reported that the data from the trial showed LX214 to be well tolerated at the two doses studied with its safety measurements indistinguishable from placebo. Besides this, clinically meaningful improvements were observed in both signs and symptoms of dry eye.

Mapracorat (formerly ZK-245186 and subsequently BOL-303242-X) is a novel, selective glucocorticoid receptor agonist developed by Bausch \& Lomb Incorporated to treat dry eye. In an animal study, it has been shown to have an anti-inflammatory efficacy similar to dexamethasone with less effect on intraocular pressure. ${ }^{76}$ In a Phase II study 
(NCT01163643), 350 patients with dry eye were randomized into BOL-303242-X $(0.3 \%, 1 \%$, and $2 \%)$ or placebo groups. The study was completed in July 2011 and no results are posted on the ClinicalTrials.gov website.

Pfizer Inc. (New York, NY, USA) developed a selective inhibitor of the Janus kinase (JAK) family (tofacitinib, also known as tasocitinib and CP-690550). JAK is involved in the activation of immune cells, proinflammatory cytokine production, and cytokine signaling. ${ }^{77}$ Tofacitinib inhibits JAK1, JAK2, and JAK3 ${ }^{78}$ Tofacitinib was employed in a Phase I/II clinical trial (NCT00784719) in dry eye patients and the results have been published. ${ }^{79}$ This was an 8-week study in which several dosage levels of tofacitinib (taken once or twice per day) were compared to vehicle and cyclosporine ophthalmic emulsion. All doses of tofacitinib exhibited a good safety profile and were well tolerated. The trial demonstrated improvement in the signs and symptoms of dry eye. These results suggest that JAK inhibitors may be useful in the treatment of dry eye.

\section{Summary and conclusion}

Currently, most dry eye patients are treated with artificial tears and/or punctal plugs. These treatments, however, may not be adequate as the disease progresses. In the last decade, only one drug (ie, Restasis) has been approved for the treatment of dry eye in the USA. Several other drugs have been approved for use in Europe (ie, Ikervis) and Asia (ie, diquafosol tetrasodium and rebamipide). In the past 10 years, many drugs have been and are currently being investigated by several different companies to treat dry eye. Some of these drugs (eg, the steroids) are being repurposed from other uses to see if they are effective in treating dry eye. New categories of drugs have also been developed to treat dry eye. These new categories of drugs are believed to treat the underlying cause of dry eye and not just act as palliative agents. The results of these investigations indicate that some of the drugs may not be good treatments for dry eye. Other drugs (eg, lifitegrast) are close to being approved by the FDA for use in the USA. In the next decade, many new drugs will be investigated and some will be approved by the FDA, which will significantly increase the treatment options for dry eye. Dry eye patients may then have their condition better controlled with these new drugs, which may decrease the cost to society of this disease.

\section{Disclosure}

The authors report no conflicts of interest in this work.

\section{References}

1. Lemp MA. Advances in understanding and managing dry eye disease. Am J Ophthalmol. 2008;146:350-356.

2. [No authors listed]. The definition and classification of dry eye disease: report of the Definition and Classification Subcommittee of the International Dry Eye WorkShop (2007). Ocul Surf. 2007;5:75-92.

3. Tomlinson A, Doane MG, McFadyen A. Inputs and outputs of the lacrimal system: review of production and evaporative loss. Ocul Surf. 2009;7:186-198.

4. Castillanos E, Torres J, Fernandez I, et al. Preponderance of evaporative over aqueous deficient-type dry eye syndrome in patients with chronic dry eye-related symptoms. Invest Ophthalmol Vis Sci. 2008;49 [Abstract 2371]:183.

5. Bron AJ, Tiffany JM. The contribution of meibomian disease to dry eye. Ocul Surf. 2004;2:149-165.

6. Schaumberg DA, Nichols JJ, Papas EB, Tong L, Uchino M, Nichols KK. The international workshop on meibomian gland dysfunction: report of the subcommittee on the epidemiology of, and associated risk factors for, MGD. Invest Ophthalmol Vis Sci. 2011;52:1994-2005.

7. Foulks GN, Bron AJ. Meibomian gland dysfunction: a clinical scheme for description, diagnosis, classification, and grading. Ocul Surf. 2003;1: $107-126$.

8. [No authors listed]. The epidemiology of dry eye disease: report of the Epidemiology Subcommittee of the International Dry Eye WorkShop (2007). Ocul Surf. 2007;5(2):93-107.

9. Schaumberg DA, Sullivan DA, Buring JE, Dana MR. Prevalence of dry eye syndrome among US women. Am J Ophthalmol. 2003;136: 318-326.

10. Moss SE, Klein R, Klein BE. Incidence of dry eye in an older population. Arch Ophthalmol. 2004;122:369-373.

11. Miljanović B, Trivedi KA, Dana MR, Gilbard JP, Buring JE, Schaumberg DA. Relation between dietary n-3 and n-6 fatty acids and clinically diagnosed dry eye syndrome in women. Am J Clin Nutr. $2005 ; 82: 887-893$.

12. Sullivan DA. Androgen deficiency and dry eye syndromes. Arch Soc Esp Oftalmol. 2004;79:49-50.

13. Sommer A. Vitamin A deficiency and the global response. Forum Nutr. 2003;56:33-35.

14. Hovanesian JA, Shah SS, Maloney RK. Symptoms of dry eye and recurrent erosion syndrome after refractive surgery. $J$ Cataract Refract Surg. 2001;27:577-584.

15. Khanal S, Tomlinson A, Esakowitz L, et al. Changes in corneal sensitivity and tear physiology after phacoemulsification. Ophthalmic Physiol Opt. 2008;28:127-134.

16. Toda I, Asano-Kato N, Komai-Hori Y, Tsubota K. Dry eye after laser in situ keratomileusis. Am J Ophthalmol. 2001;132:1-7.

17. Farris RL. The dry eye: its mechanisms and therapy, with evidence that contact lens is a cause. CLAO J. 1986;12:234-246.

18. Dogru M, Tsubota K. New insights into the diagnosis and treatment of dry eye. Ocul Surf. 2004;2:59-75.

19. Begley CG, Chalmers RL, Abetz L, et al. The relationship between habitual patient-reported symptoms and clinical signs among patients with dry eye of varying severity. Invest Ophthalmol Vis Sci. 2003;44:4753-4761.

20. Himebaugh NL, Begley CG, Bradley A, Wilkinson JA. Blinking and tear break-up during four visual tasks. Optom Vis Sci. 2009;86: E106-E114.

21. Donshik PC, Sall K, Cacioppo L, et al. Presenting symptoms from diary cards for dry eye clinical trial subjects. Invest Ophthalmol Vis Sci. 2002;43 [Abstract 3067]:124.

22. Johnson ME. The association between symptoms of discomfort and signs in dry eye. Ocul Surf. 2009;7:199-211.

23. Nichols KK, Nichols JJ, Mitchell GL. The lack of association between signs and symptoms in patients with dry eye disease. Cornea. 2004;23: 762-770.

24. Yu J, Asche CV, Fairchild CJ. The economic burden of dry eye disease in the United States: a decision tree analysis. Cornea. 2011;30: 379-387. 
25. Dry eye syndrome treatment market to grow by nearly $\$ 4$ billion in the next decade [press release]. London: GlobalData; 2013 [June 12]. Available from: http://healthcare.globaldata.com/media-center/pressreleases/pharmaceuticals/dry-eye-syndrome-treatment-market-to-growby-nearly-4-billion-in-the-next-decade. Accessed June 16, 2015.

26. [No authors listed]. Management and therapy of dry eye disease: report of the Management and Therapy Subcommittee of the International Dry Eye WorkShop (2007). Ocul Surf. 2007;5(2):163-178.

27. Patane MA, Cohen A, From S, Torkildsen G, Welch D, Ousler GW 3rd. Ocular iontophoresis of EGP-437 (dexamethasone phosphate) in dry eye patients: results of a randomized clinical trial. Clin Ophthalmol. 2011;5:633-643.

28. Kala Pharmaceuticals announces positive results from Phase 2 trial of KPI121 in dry eye disease [press release]. Waltham, MA: Kala Pharmaceuticals; Watson K, Marshall H; MacDougall Biomedical Communications; 2015 [April 1]. Available from: http://kalarx.com/wp-content/uploads/ docs/Kala_--_dry_eye_press_release_01APR2015_en.pdf. Accessed June 16, 2015.

29. Baklayan GA, Muñoz M. The ocular distribution of (14)C-labeled bromfenac ophthalmic solution $0.07 \%$ in a rabbit model. Clin Ophthalmol. 2014;8:1717-1724.

30. Rajpal RK, Ross B, Rajpal SD, Hoang K. Bromfenac ophthalmic solution for the treatment of postoperative ocular pain and inflammation: safety, efficacy, and patient adherence. Patient Prefer Adherence. 2014;8:925-931.

31. Fujishima H, Fuseya M, Ogata M, Murat D. Efficacy of bromfenac sodium ophthalmic solution for treatment of dry eye disease. Asia Pac J Ophthalmol (Phila). 2015;4:9-13.

32. Hou J, Townson SA, Kovalchin JT, et al. Design of a superior cytokine antagonist for topical ophthalmic use. Proc Natl Acad Sci U S A. 2013;110:3913-3918.

33. Okanobo A, Chauhan SK, Dastjerdi MH, Kodati S, Dana R. Efficacy of topical blockade of interleukin-1 in experimental dry eye disease. Am J Ophthalmol. 2012;154:63-71.

34. Tubridy K, Goldstein MH, Agahigian J, et al. Clinical development of EBI-005, a novel interleukin-1 receptor inhibitor, for patients with ocular surface inflammation. Invest Ophthalmol Vis Sci. 2015;56:4488.

35. Assier E, Boissier MC, Dayer JM. Interleukin-6: from identification of the cytokine to development of targeted treatments. Joint Bone Spine. 2010;77:532-536.

36. Bunya VY, Revere K, Iwabe S, et al. Safety and efficacy of topical tocilizumab in a canine model. Invest Ophthalmol Vis Sci. 2014;55:1485.

37. Baharav E, Bar-Yehuda S, Madi L, et al. Antiinflammatory effect of A3 adenosine receptor agonists in murine autoimmune arthritis models. J Rheumatol. 2005;32:469-476.

38. Bar-Yehuda S, Rath-Wolfson L, Del Valle L, et al. Induction of an antiinflammatory effect and prevention of cartilage damage in rat knee osteoarthritis by CF101 treatment. Arthritis Rheum. 2009;60 3061-3071.

39. Ochaion A, Bar-Yehuda S, Cohn S, et al. Methotrexate enhances the anti-inflammatory effect of CF101 via up-regulation of the A3 adenosine receptor expression. Arthritis Res Ther. 2006;8:R169.

40. Mabley J, Soriano F, Pacher P, et al. The adenosine A3 receptor agonist, N6-(3-iodobenzyl)-adenosine- $5^{\prime}$-N-methyluronamide, is protective in two murine models of colitis. Eur J Pharmacol. 2003;466: 323-329.

41. Bar-Yehuda S, Silverman MH, Kerns WD, Ochaion A, Cohen S, Fishman P. The anti-inflammatory effect of A3 adenosine receptor agonists: a novel targeted therapy for rheumatoid arthritis. Expert Opin Investig Drugs. 2007;16:1601-1613.

42. Lee HT, Kim M, Joo JD, Gallos G, Chen JF, Emala CW. A3 adenosine receptor activation decreases mortality and renal and hepatic injury in murine septic peritonitis. Am J Physiol Regul Integr Comp Physiol. 2006;291:R959-R969.

43. Avni I, Garzozi HJ, Barequet IS, et al. Treatment of dry eye syndrome with orally administered CF101: data from a phase 2 clinical trial. Ophthalmology. 2010;117:1287-1293.
44. Lallemand F, Daull P, Benita S, Buggage R, Garrigue JS. Successfully improving ocular drug delivery using the cationic nanoemulsion, novasorb. J Drug Deliv. 2012;2012:604204.

45. Daull P, Feraille L, Barabino S, Garrigue JS. Efficacy evaluation of a cationic emulsion of cyclosporine in a mouse model of dry eye. Invest Ophthalmol Vis Sci 2015;56:4468.

46. Santen announces approval of Ikervis for EU marketing authorization [press release]. Osaka: Santen Pharmaceutical Co., Ltd.; 2015 [March 25]. Available from: http://www.santen.com/en/news/20150325.pdf. Accessed June 16, 2015.

47. Sheppard JD, Torkildsen GL, Lonsdale JD, et al. Lifitegrast ophthalmic solution $5.0 \%$ for treatment of dry eye disease: results of the OPUS-1 phase 3 study. Ophthalmology. 2014;121:475-483.

48. Nichols KK, Majmudar PA, Donnenfeld ED, Raychadhuri A, Semba CP. A one-year, multicenter, randomized, double-masked placebo-controlled study of lifitegrast ophthalmic solution $5.0 \%$ in patients with dry eye: findings for subjects electing to use artificial tears. Invest Ophthalmol Vis Sci. 2015;56:325.

49. Nichols JJ, Bickle KM,Zink RC, Schiewe MD, Haque RM, Nichols KK. Safety and efficacy of topical azithromycin ophthalmic solution $1.0 \%$ in the treatment of contact lens-related dry eye. Eye Contact Lens. 2012;38:73-79.

50. Veldman P, Colby K. Current evidence for topical azithromycin 1\% ophthalmic solution in the treatment of blepharitis and blepharitisassociated ocular dryness. Int Ophthalmol Clin. 2011;51:43-52.

51. Gottenberg JE, Ravaud P, Puéchal X, et al. Effects of hydroxychloroquine on symptomatic improvement in primary Sjögren syndrome: the JOQUER randomized clinical trial. JAMA. 2014;312:249-258.

52. Rihl M, Ulbricht K, Schmidt RE, Witte T. Treatment of sicca symptoms with hydroxychloroquine in patients with Sjogren's syndrome. Rheumatology (Oxford). 2009;48:796-799.

53. Yavuz S, Asfuroğlu E, Bicakcigil M, Toker E. Hydroxychloroquine improves dry eye symptoms of patients with primary Sjogren's syndrome. Rheumatol Int. 2011;31:1045-1049.

54. Opremcak EM. Plaquenil toxicity. Insight. 2013;38:15.

55. Vanderzee G, Tassi D. New trends in early diagnosis of hydroxychloroquine toxic retinopathy. Optometry. 2012;83:200-207.

56. Devauchelle-Pensec V, Mariette X, Jousse-Joulin S, et al. Treatment of primary Sjögren syndrome with rituximab: a randomized trial. Ann Intern Med. 2014;160:233-242.

57. Meerovitch K, Brazzell K, Ousler GW 3rd, Cumberlidge G. Improvements in signs and symptoms of dry eye with MIM-D3 1\% ophthalmic solution compared to placebo in different patient populations. In Association for Research in Vision and Ophthalmology, Inc. 2015 Annual Meeting Abstracts. Abstract A0086. Available from: http://www. arvo.org/webs/am2015/abstract/438.pdf. Accessed June 16, 2015.

58. Arakawa T, Kobayashi K, Yoshikawa T, Tarnawski A. Rebamipide: overview of its mechanisms of action and efficacy in mucosal protection and ulcer healing. Dig Dis Sci. 1998;43:5S-13S.

59. Urashima H, Okamoto T, Takeji Y, Shinohara H, Fujisawa S. Rebamipide increases the amount of mucin-like substances on the conjunctiva and cornea in the N-acetylcysteine-treated in vivo model. Cornea. 2004;23:613-619.

60. Itoh S, Itoh K, Shinohara H. Regulation of human corneal epithelial mucins by rebamipide. Curr Eye Res. 2014;39:133-141.

61. Takeji Y, Urashima H, Aoki A, Shinohara H. Rebamipide increases the mucin-like glycoprotein production in corneal epithelial cells. J Ocul Pharmacol Ther. 2012;28:259-263.

62. Satake Y, Higa K, Dogru M, Mitamura H, Toriyama N, Shimazaki J. The effect of rebamipide to the human conjunctival epithelium. Invest Ophthalmol Vis Sci. 2014;55:3697.

63. Kinoshita S, Awamura S, Nakamichi N, Suzuki H, Oshiden K, Yokoi N; Rebamipide Ophthalmic Suspension Long-term Study Group. A multicenter, open-label, 52-week study of 2\% rebamipide (OPC-12759) ophthalmic suspension in patients with dry eye. Am J Ophthalmol. 2014;157:576-583. e1

64. Kashima T, Itakura H, Akiyama H, Kishi S. Rebamipide ophthalmic suspension for the treatment of dry eye syndrome: a critical appraisal. Clin Ophthalmol. 2014;8:1003-1010. 
65. Jumblatt JE, Jumblatt MM. Regulation of ocular mucin secretion by P2Y2 nucleotide receptors in rabbit and human conjunctiva. Exp Eye Res. 1998;67:341-346.

66. Murakami T, Fujihara T, Horibe Y, Nakamura M. Diquafosol elicits increases in net $\mathrm{Cl}$ - transport through $\mathrm{P} 2 \mathrm{Y} 2$ receptor stimulation in rabbit conjunctiva. Ophthalmic Res. 2004;36:89-93.

67. Tauber J, Davitt WF, Bokosky JE, et al. Double-masked, placebocontrolled safety and efficacy trial of diquafosol tetrasodium (INS365) ophthalmic solution for the treatment of dry eye. Cornea. 2004;23: 784-792.

68. Takamura E, Tsubota K, Watanabe H, Ohashi Y; Diquafosol Ophthalmic Solution Phase 3 Study Group. A randomised, double-masked comparison study of diquafosol versus sodium hyaluronate ophthalmic solutions in dry eye patients. Br J Ophthalmol. 2012;96:1310-1315.

69. Gong L, Sun X, Ma Z, et al. A randomised, parallel-group comparison study of diquafosol ophthalmic solution in patients with dry eye in China and Singapore. Br J Ophthalmol. 2015;99:903-908.

70. Koh S. Clinical utility of $3 \%$ diquafosol ophthalmic solution in the treatment of dry eyes. Clin Ophthalmol 2015;9:865-872.

71. Sosne G, Szliter EA, Barrett R, Kernacki KA, Kleinman H, Hazlett LD. Thymosin beta 4 promotes corneal wound healing and decreases inflammation in vivo following alkali injury. Exp Eye Res. 2002;74:293-299.

72. Sosne G, Dunn SP, Kim C. Thymosin $\beta 4$ significantly improves signs and symptoms of severe dry eye in a phase 2 randomized trial. Cornea. 2015;34:491-496.
73. Perekhvatova N, Petrov A, Friedhoff L, Ousler GW. Evaluation of antioxidant SkQ1 as a treatment for the signs and symptoms of dry eye. Invest Ophthalmol Vis Sci. 2015;56:4481.

74. de Paiva CS, Schwartz CE, Gjörstrup P, Pflugfelder SC. Resolvin E1 (RX-10001) reduces corneal epithelial barrier disruption and protects against goblet cell loss in a murine model of dry eye. Cornea. 2012;31: 1299-1303.

75. Li N, He J, Schwartz CE, Gjorstrup P, Bazan HE. Resolvin E1 improves tear production and decreases inflammation in a dry eye mouse model. J Ocul Pharmacol Ther. 2010;26:431-439.

76. Shafiee A, Bucolo C, Budzynski E, Ward KW, López FJ. In vivo ocular efficacy profile of mapracorat, a novel selective glucocorticoid receptor agonist, in rabbit models of ocular disease. Invest Ophthalmol Vis Sci. 2011;52:1422-1430.

77. Ghoreschi K, Laurence A, O'Shea JJ. Janus kinases in immune cell signaling. Immunol Rev. 2009;228:273-287.

78. Meyer DM, Jesson MI, Li X, et al. Anti-inflammatory activity and neutrophil reductions mediated by the JAK1/JAK3 inhibitor, CP-690,550, in rat adjuvant-induced arthritis. J Inflamm (Lond). 2010;7:41.

79. Liew SH, Nichols KK, Klamerus KJ, Li JZ, Zhang M, Foulks GN. Tofacitinib (CP-690,550), a Janus kinase inhibitor for dry eye disease: results from a phase 1/2 trial. Ophthalmology. 2012;119: 1328-1335.

80. Behrens A, Doyle JJ, Stern L, et al. Dysfunctional tear syndrome: A Delphi approach to treatment recommendations. Cornea. 2006;25(8):900-907.
Clinical Optometry

\section{Publish your work in this journal}

Clinical Optometry is an international, peer-reviewed, open access journal publishing original research, basic science, clinical and epidemiological studies, reviews and evaluations on clinical optometry. All aspects of patient care are addressed within the journal as well as the practice of optometry including economic and business analyses. Basic and clinical

\section{Dovepress}

research papers are published that cover all aspects of optics, refraction and its application to the theory and practice of optometry. The manuscript management system is completely online and includes a very quick and fair peer-review system, which is all easy to use. Visit http://www.dovepress. com/testimonials.php to read real quotes from published authors. 